\title{
Laccase immobilized onto graphene oxide nanosheets and electrodeposited gold-cetyltrimethylammonium bromide complex to fabricate a novel catechol biosensor
}

\author{
MARYAM NAZARI ${ }^{1,2}$, SOHEILA KASHANIAN ${ }^{1,2, *}$, NASIM MALEKI ${ }^{1}$ \\ and NAHID SHAHABADI ${ }^{1,3}$ \\ ${ }^{1}$ Faculty of Chemistry, Razi University, Kermanshah 67149, Iran \\ ${ }^{2}$ Nano Drug Delivery Research Center, Faculty of Pharmacy, Kermanshah University of Medical Sciences, Kermanshah \\ 6715847141, Iran \\ ${ }^{3}$ Medical Biology Research Center, Kermanshah University of Medical Sciences, Kermanshah 6715847141, Iran \\ *Author for correspondence (kashanian_s@yahoo.com)
}

MS received 23 April 2018; accepted 9 August 2018; published online 21 February 2019

\begin{abstract}
In this study, a new biosensor is developed with reliable and easy-to-use biodevice properties for catechol determination in real samples. A method is proposed for the fabrication of biosensors to sense catechol based on the adsorption method of laccase immobilization. Hence, a glassy carbon electrode was modified via graphene oxide nanosheets and then it was modified with a gold-cetyltrimethylammonium bromide nanocomposite to adsorb and immobilize laccase on the electrode surface. The results showed laccase immobilization onto the reformed glassy carbon electrode, and a direct electron transfer reaction between laccase and the electrode. The mechanism of electron transferring was $\mathrm{EC}^{\prime}$. Also, $k_{\mathrm{S}}$ and $\alpha$ were calculated as $0.41 \mathrm{~s}^{-1}$ and 0.33 , respectively. For this biosensor two linear ranges, $0.1 \times 10^{-6}$ to $5 \times 10^{-6} \mathrm{M}$ and $16.7 \times 10^{-6}$ to $166 \times 10^{-6} \mathrm{M}$, and a detection limit of $1.5 \times 10^{-6} \mathrm{M}$ were obtained.
\end{abstract}

Keywords. Biosensor; laccase; graphene oxide; gold-cetyltrimethylammonium bromide complex; catechol.

\section{Introduction}

The health of organisms is affected by phenolic compounds. These compounds release into ground and surface waters is occurred due to their utilization in product fabrication among oil refining, coal conversion, medicines, surfactants, pesticides, colourants, plastics and resin formation [1-3]. European Community announced that the maximum amount of phenols in effluent should be $<1 \mathrm{ppm}$ [4]. Phenols can be detected by various analytical techniques, such as spectrophotometry, capillary electrophoresis and liquid and gas chromatographies [5,6]. These techniques do not have high sensitivity and specificity and also they require time, sample pre-treatment, costly equipment and skilled operators $[7,8]$. Biosensors are sensitive, cost-effective and portable systems compared to the other techniques [9]. Biosensors are used to detect phenol in clinical and biomedical areas, samples of environmental contamination, industrial and pharmaceutical analysis. Electrochemical biosensors are more common [10]. Laccase (Lac), tyrosinase (Tyr) and horseradish peroxidase (HRP) have attracted considerable attention for electrochemical biosensor fabrication in the phenol detection field [11-13]. These three enzymes have different reaction mechanisms. HRP is oxidized by hydrogen peroxide $\left(\mathrm{H}_{2} \mathrm{O}_{2}\right)$ and can be acquired again by oxidizing of phenolic compounds [13,14]. Phenolics without any substituent groups are able to be oxidized by Tyr [10]. Lac can oxidize phenols without substituent groups in meta- and para-positions [15]. Lac biosensors fabrication has been followed for phenol detection as a fascinating subject in a broad range. Lac (EC 1.10.3.2), a copper-containing oxidase [16] exists in insects, fungi, plants and some bacteria [17]. In addition to phenols, it is able to catalyse anilines and benzenethiols oxide-forms with the attendant $\mathrm{O}_{2}$ reduction and water production [18], via free radical mechanism [19]. Different biosensor fabrications have been reported based on Lac immobilization onto many supports, such as matrix of mesoporous silica sieve/polyvinyl alcohol [20] and modified screen-printed electrodes modified with carbon black [21] through adsorption; cyanuric chloride in chitosan by cross-linking [22]; graphite electrodes [23] and nanohybrid of reduced graphene oxide (rGO)-glycol chitosan [24] by covalent coupling.

The use of nanomaterials and nanoparticles (NPs) affects biosensors' analytic performance. Graphene is an ideal material in the making of electrochemical biosensors because of electrical conductivity, mechanical pliability, high-thermal conductivity, vast specific surface area and good adaptability [25]. It is a good candidate for many applications and also for the construction of sensitive biosensors [26]. Veerapandian 
et al [27] proposed the detection of quercetin utilizing a covalent reaction of graphene oxide (GO) with NPs of silver and silica-polyethylene glycol placed on-chip with a good linear range and low detection limit. Modifying the graphene with metal NPs (MNPs) makes it stable and value-effective biosensors. Gold NPs (AuNPs) have special properties including high conductivity, vigorous adsorption ability and promoting electron transfer. Using good stabilizers such as surfactants can accelerate the amount of metal particle formation and also protect the MNPs from agglomeration [28,29]. Amlodipine and enalapril were determined simultaneously using a paste electrode reformed with multiwalled carbon nanotubes (MWCNTs) and cetyltrimethylammonium bromide (CTAB). The outcomes showed that the CTAB could be adsorbed on the oxidized MWCNTs and influenced the electrochemical response of analytes [30]. Surfactants provide better molecule orientation at the electrode interface and affect electron transferring of electroactive species at the surface of bare metal electrode [28]. It was reported that $\left[\mathrm{AuCl}_{4}\right]^{-}$interacts with CTAB prior to the reduction process [31] and the reductions of $\mathrm{AuCl}_{4}^{-}$to $\mathrm{AuCl}_{2}^{-}$and $\mathrm{AuCl}_{2}^{-}$to $\mathrm{Au}^{0}$ are electropositive reactions. $\mathrm{AuCl}_{2}^{-}$can bind strongly to the CTAB micelles [32].

In this study, we fabricated a Lac biosensor using GO nanosheets, a cationic surfactant (CTAB) and AuNPs for immobilization of Lac to detect catechol. The modified electrode has high-catalytic activity for catechol determination. GO nanosheets have negative charge due to the presence of many oxygen groups. It was placed onto the bare glassy carbon electrode (GCE); then the second layer, i.e., Au-CTAB complex (Au-CTAB) was electrodeposited, and finally, Lac with negative charge was immobilized.

\section{Experimental}

\subsection{Materials and reagents}

Lac (from the source of Trametes versicolor, $21.8 \mathrm{U}$ per mg) was provided by Sigma Aldrich. It was used without further purification. Catechol was purchased from Merck. $\mathrm{HAuCl}_{4}$ and CTAB were obtained from PubChem and Sigma, respectively. All other chemicals were purchased from Merck. Distilled deionized water was used for the preparation of all solutions.

\subsection{Apparatus}

A Sama 500 electro-analyzer system was used for carrying out voltammetry techniques (differential pulse voltammetry (DPV) and cyclic voltammetry (CV)). Three electrodes (purchased from Azar Electrode) were placed in an electrochemical cell; an $\mathrm{Ag} / \mathrm{AgCl}$ (saturated $\mathrm{KCl}$ ) as a reference electrode, GCE as a working electrode and a $\mathrm{Pt}$ rod as a counter electrode were used. The electrochemical impedance spectroscopy (EIS) technique was carried out on an Autolab (Eco Chemie BV, The Netherlands) in the solution comprising $5.0 \times 10^{-3} \mathrm{M} \mathrm{K}_{4}\left[\mathrm{Fe}(\mathrm{CN})_{6}\right] / \mathrm{K}_{3}\left[\mathrm{Fe}(\mathrm{CN})_{6}\right]$ and $1.0 \times 10^{-1} \mathrm{M} \mathrm{KCl}$. To characterize the electrode surface morphology, scanning electron microscopy (SEM) and fieldemission scanning electron microscopy (FESEM) (MIRA3 TESCAN) were employed.

\subsection{Preparation of Lac/nano-Au/CTAB/GO/GCE}

GO was obtained by an improved modified Hummers method [33]. A GCE was cleaned with alumina grouts and well emery paper sheet and was washed with distilled deionized water, then dried at room temperature. A suspension of GO was prepared in water ( $2 \mathrm{mg}$ GO in $10 \mathrm{ml}$ water); after sonicating, $5 \mu l$ of its suspension was dropped on the GCE surface and the water was taken out. By the addition of CTAB to the $\mathrm{HAuCl}_{4}$ solution, a yellow/orange color solution was attained (micelles are formed from a water-insoluble complex). There were electrostatic attractions between the CTAB positive head group and anion complexes to offer the binding interaction [32]. Subsequently, in a yellow/orange colour solution comprising $1.0 \times 10^{-1} \mathrm{M} \mathrm{KNO}_{3}, 1.0 \times 10^{-4} \mathrm{M} \mathrm{HAuCl}_{4}$ and $5.0 \times 10^{-4} \mathrm{M}$ CTAB, the modified GCE was treated under the fixed potential of $-0.4 \mathrm{~V}$ ( $v s . \mathrm{Ag} / \mathrm{AgCl}$ ) for $300 \mathrm{~s}$ to achieve $\mathrm{Au}-\mathrm{CTAB} / \mathrm{GO} / \mathrm{GCE}$. The modified GCE was then picked up and thoroughly washed with distilled deionized water to eliminate the physically absorbed $\mathrm{HAuCl}_{4}$ and CTAB. Then, it was potential scanned in phosphate buffer to gain a steady state. The enzyme solution was prepared in phosphate buffer $(\mathrm{pH} 6$, $1.0 \times 10^{-1} \mathrm{M}$ ) with the concentration of $3.3 \mathrm{mg}$ per $\mathrm{ml}$ ( Lac has negative charge at $\mathrm{pH}$ 6). Lac immobilization on the modified GCE was performed by dropping $5 \mu$ l of Lac solution on the electrode surface, and then it was washed with phosphate buffer. While the biosensor was not in use, it was kept in a fridge at $4{ }^{\circ} \mathrm{C}$.

\subsection{Biosensor characterization using various techniques}

For characterization of the modified electrode, the following techniques were employed: Energy Dispersive Spectroscopy (EDS), FESEM, SEM, Fourier-transform infrared (FTIR) spectroscopy and electrochemical methods. Using SEM and FESEM, the morphology of deposited multilayered structures at the nanometre level was demonstrated. EIS was performed in solution containing an electroactive probe $\left(\mathrm{K}_{4}\left[\mathrm{Fe}(\mathrm{CN})_{6}\right] / \mathrm{K}_{3}\left[\mathrm{Fe}(\mathrm{CN})_{6}\right]\right)$ to measure the impedance changes of the prepared electrodes. Voltammetry techniques were used to examine biosensing characteristics in the presence of catechol. Experimentations were carried out with SAMA 500 electro-analyzer to obtain CV and DPV data. An electrochemical cell was utilized with three electrodes using the GCE, $\mathrm{Pt}$ rod and $\mathrm{Ag} / \mathrm{AgCl}$ electrode. Cyclic voltammograms were registered at the scan rate of $1.0 \times$ $10^{-1} \mathrm{~V} \mathrm{~s}^{-1}$ from -0.5 to $0.8 \mathrm{~V}$ in the presence of catechol and $\mathrm{K}_{3} \mathrm{Fe}(\mathrm{CN})_{6} / \mathrm{K}_{4} \mathrm{Fe}(\mathrm{CN})_{6}$. 

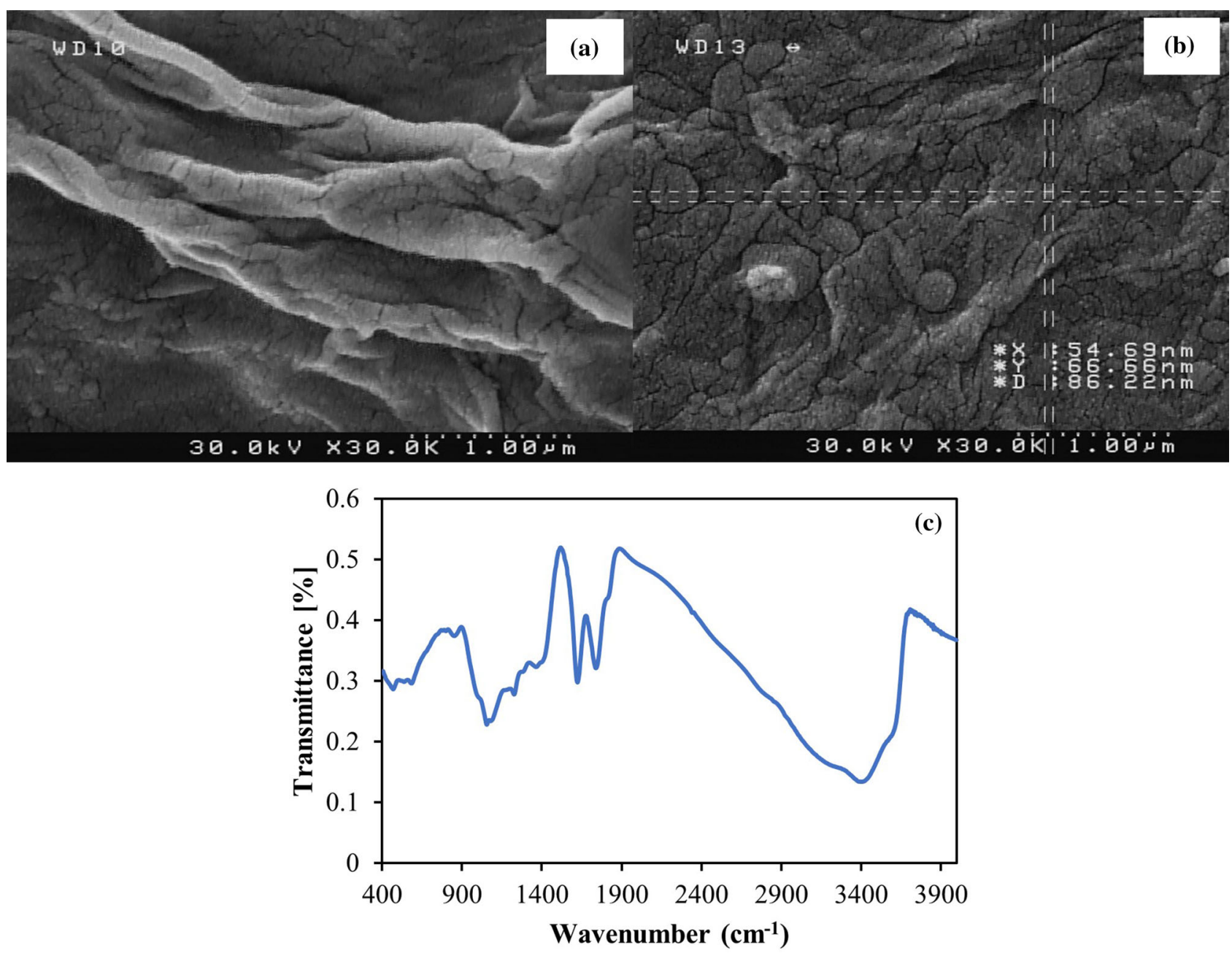

Figure 1. SEM images of modified electrodes: (a) GO/GCE, (b) Au-CTAB/GO/GCE and (c) GO FTIR spectrum.
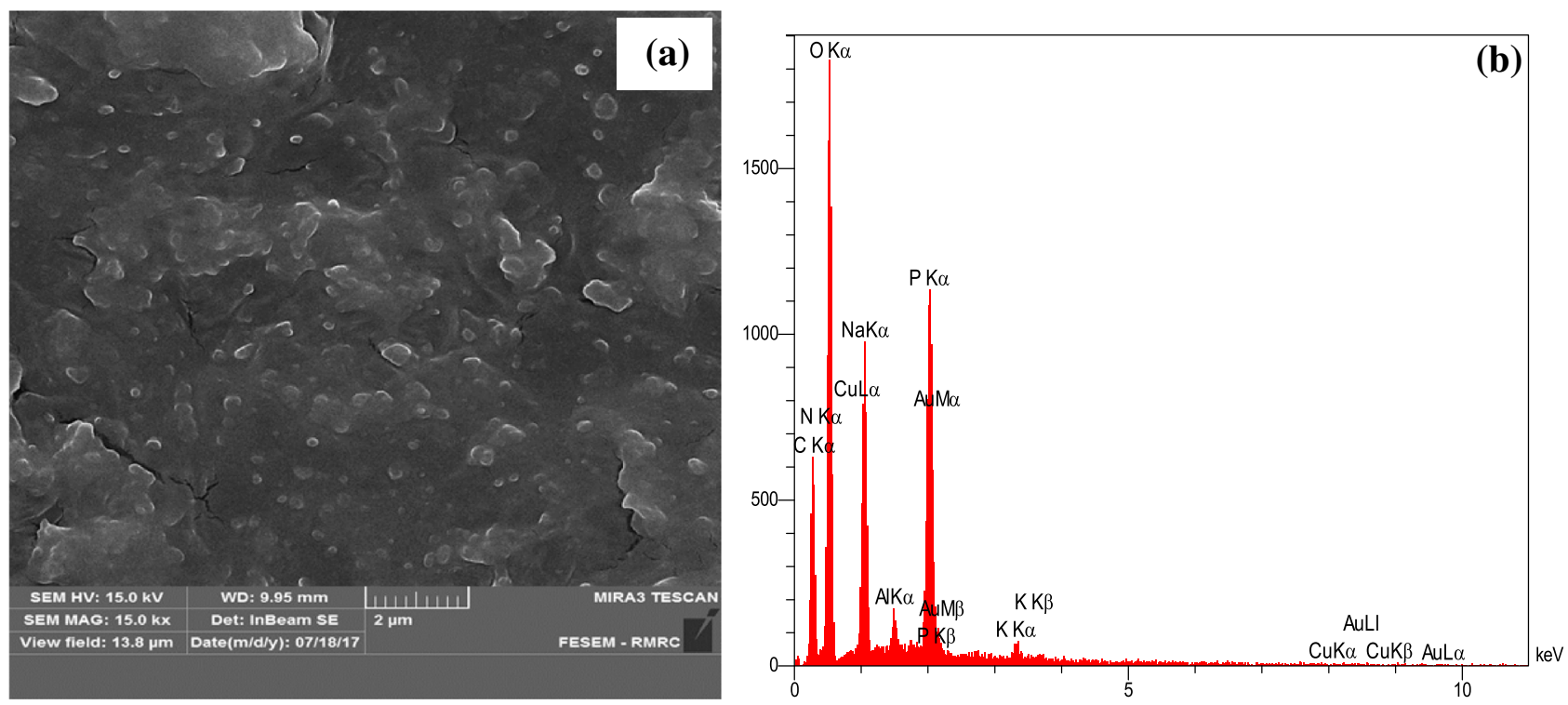

Figure 2. (a) FESEM image and (b) EDS spectrum of Lac/Au-CTAB/GO/GCE. 

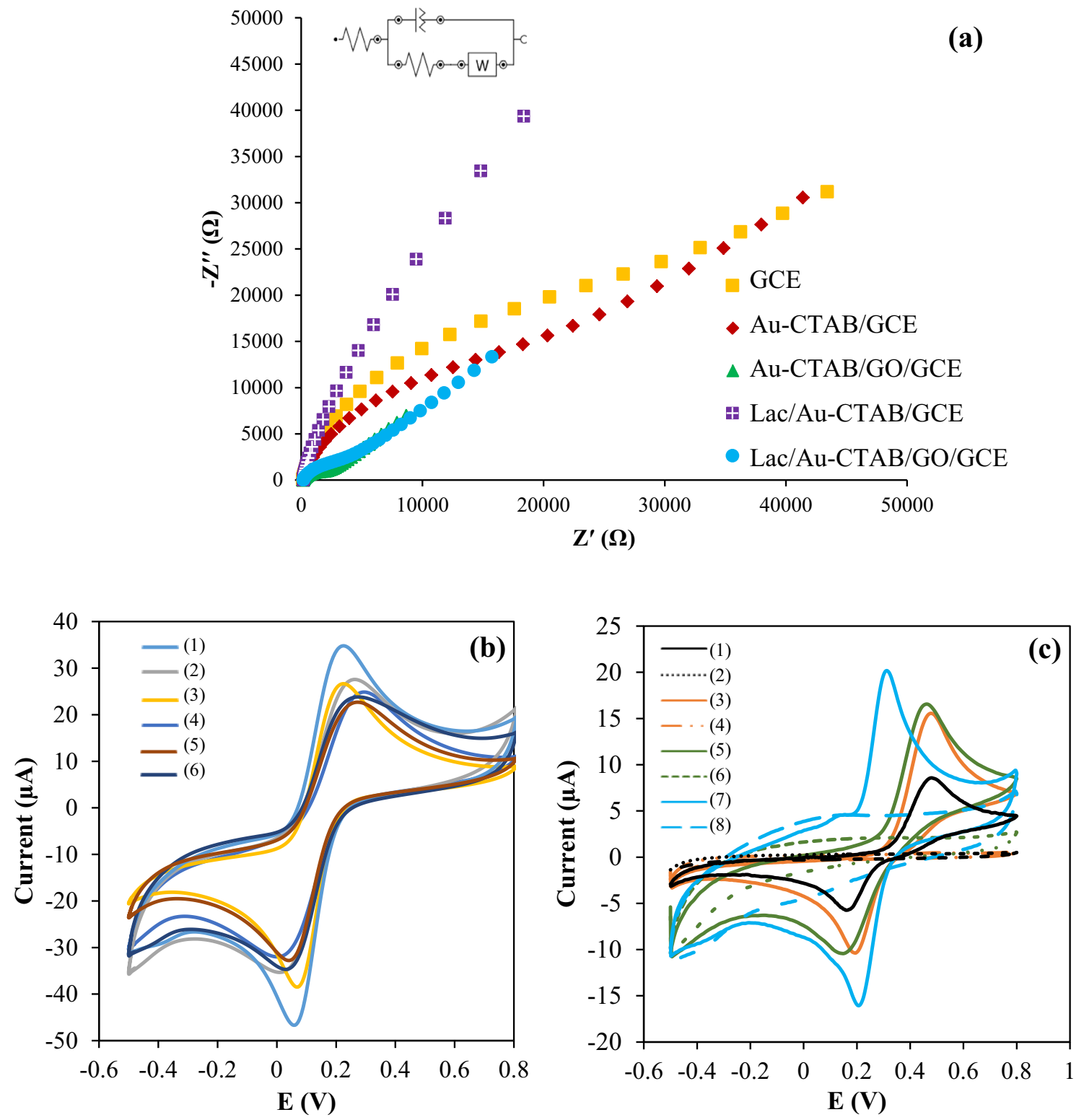

Figure 3. (a) EIS of the bare GCE, $\mathrm{Au}-\mathrm{CTAB} / \mathrm{GCE}, \mathrm{Au}-\mathrm{CTAB} / \mathrm{GO} / \mathrm{GCE}, \mathrm{Lac} / \mathrm{Au}-\mathrm{CTAB} / \mathrm{GCE}$ and $\mathrm{Lac} / \mathrm{Au}-$ CTAB/GO/GCE. Inset: the EIS circuit of GCE, Au-CTAB/GCE, Au-CTAB/GO/GCE and Lac/Au-CTAB/GO/GCE. (b) CVs of Au-CTAB/GO/GCE (1) GO/GCE (2), Au-CTAB/GCE (3), GCE (4) Lac/Au-CTAB/GCE (5) and Lac/Au$\mathrm{CTAB} / \mathrm{GO} / \mathrm{GCE}(6)$ in the presence of $\mathrm{K}_{3} \mathrm{Fe}(\mathrm{CN})_{6}\left(5.0 \times 10^{-3} \mathrm{M}\right)$ and $\mathrm{KCl}(0.1 \mathrm{M})$. (c) CVs of GCE (1) GO/GCE (3), $\mathrm{Lac} / \mathrm{Au}-\mathrm{CTAB} / \mathrm{GCE}$ (5) and Lac/Au-CTAB/GO/GCE (7) in phosphate buffer (pH 5) and CVs of GCE (2) GO/GCE (4), $\mathrm{Lac} / \mathrm{Au}-\mathrm{CTAB} / \mathrm{GCE}(6)$ and $\mathrm{Lac} / \mathrm{Au}-\mathrm{CTAB} / \mathrm{GO} / \mathrm{GCE}(8)$ in the presence of catechol $\left(1.0 \times 10^{-3} \mathrm{M}\right)$.

\section{Results and discussion}

\subsection{Morphology of electrodes}

The SEM images show the surface morphologies of electrodes modified with GO nanosheets and Au-CTAB (figure 1a and b). The bare GCE has a flat surface, so the layer structure of $\mathrm{GO}$ at $\mathrm{GO} / \mathrm{GCE}$ can be detected (figure 1a). For the surface related to $\mathrm{Au}-\mathrm{CTAB} / \mathrm{GO} / \mathrm{GCE}$, there are NPs on GO sheets and many NPs with the dimensions of $<100 \mathrm{~nm}$ were distributed uniformly on the electrode surface (figure 1b). It is a good evidence to confirm electrochemical stabilization of $\mathrm{Au}-\mathrm{CTAB}$ on the surface of GCE merely using a onestep route. The GO sheets increase the electrodeposition of $\mathrm{Au}-\mathrm{CTAB}$ because of its vast surface area (figure 1b). Additionally, functional groups were detected using FTIR studies. As shown in figure 1c, the spectrum of GO exhibits main peaks at $1059,1230,1624$ and $1741 \mathrm{~cm}^{-1}$ that are related to 

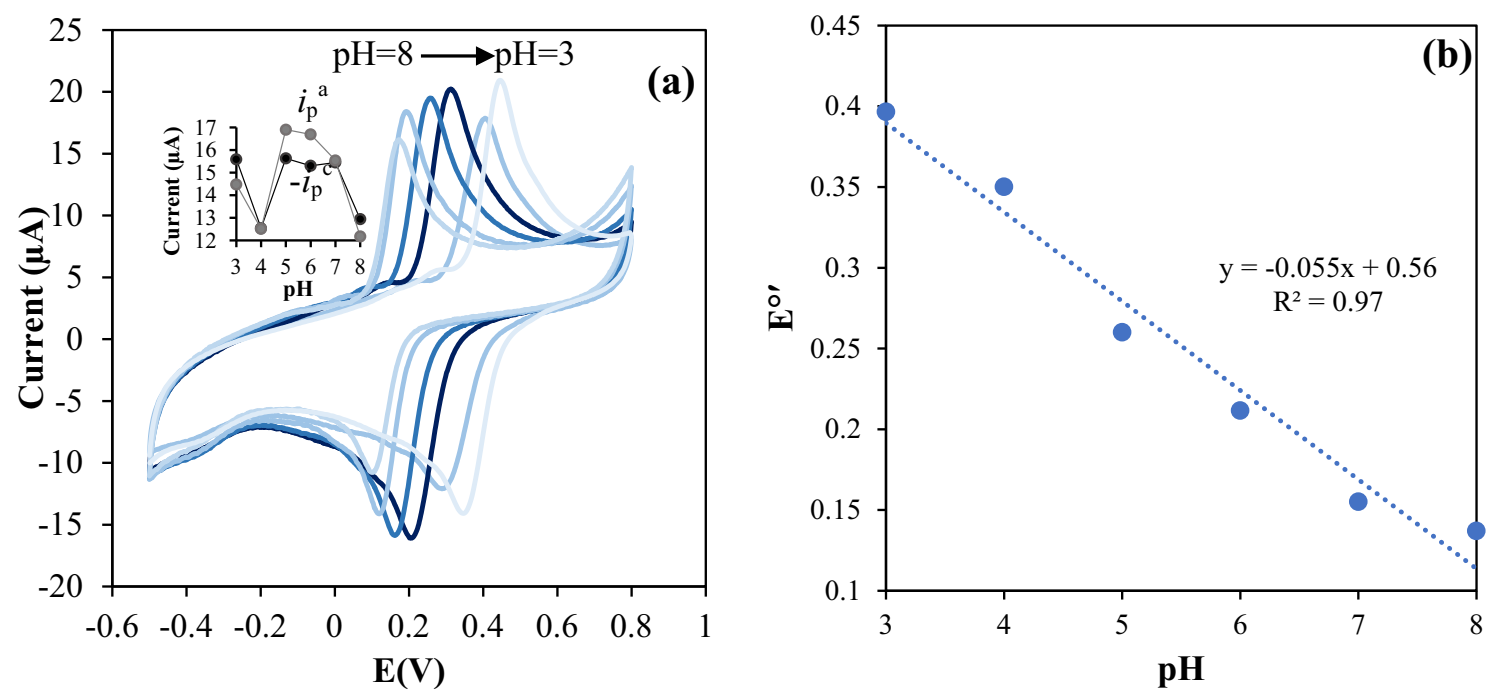

Figure 4. (a) The influence of $\mathrm{pH}$ on the peak current of catechol redox reaction for Lac biosensor. Inset: the effect of cathodic and anodic currents vs. pH. (b) Dependency of $E^{\circ \prime}$ against $\mathrm{pH}$.

the bands of $\mathrm{C}-\mathrm{O}-\mathrm{C}$ in alkoxy or epoxy groups, $\mathrm{C}=\mathrm{C}, \mathrm{C}-\mathrm{OH}$ and $\mathrm{C}=\mathrm{O}$ in carboxylic acid and carbonyl groups [34].

Figure 2a shows the FESEM image of Lac/Au-CTAB/GO/ GCE morphology. Also, EDS analysis confirmed the presence of Lac. It showed the existence of $\mathrm{N}, \mathrm{O}, \mathrm{C}, \mathrm{Cu}, \mathrm{Au}, \mathrm{Na}, \mathrm{K}$ and $\mathrm{P}$ components (figure $2 \mathrm{~b}$ ); $\mathrm{Cu}$ is related to $\mathrm{Lac}$.

\subsection{EIS}

EIS demonstrates the impedance variations of the modified electrodes. At the electrode interface, electron-transfer resistance $\left(R_{\mathrm{et}}\right)$ controls the redox probe electron transfer kinetics and it was obtained from a semicircle diameter. figure 3a illustrates the typical Nyquist plots of GCE, AuCTAB/GCE, Au-CTAB/GO/GCE, Lac/Au-CTAB/GCE and $\mathrm{Lac} / \mathrm{Au}-\mathrm{CTAB} / \mathrm{GO} / \mathrm{GCE} . R_{\text {et }}$ can be obtained from the circuits that are shown in figure $3 \mathrm{a}$ inset. The applied potentials for the modified electrodes were $0.283,0.268,0.249,0.212$ and $0.229 \mathrm{~V}$ for GCE, Au-CTAB/GCE, Lac/Au-CTAB/GCE, $\mathrm{Au}-\mathrm{CTAB} / \mathrm{GO} / \mathrm{GCE}$ and $\mathrm{Lac} / \mathrm{Au}-\mathrm{CTAB} / \mathrm{GO} / \mathrm{GCE}$, respectively. The Nyquist plots of GCE, Au-CTAB/GCE, Lac/AuCTAB/GCE, Au-CTAB/GO/GCE and Lac/Au-CTAB/GO/ GCE displayed semicircles with the values of about 30.6, $20.5,43.9,1.88$ and $3.56 \mathrm{k} \Omega$ of $R_{\mathrm{et}}$, respectively. The $R_{\mathrm{et}}$ value which is the smallest for $\mathrm{Au}-\mathrm{CTAB} / \mathrm{GO} / \mathrm{GCE}$ indicates that the interaction between the Au-CTAB composite and GO stimulates electron transferring of electrochemical probes. For enzymatic modified electrodes, it can be seen that the $R_{\mathrm{et}}$ values are obtained larger than for the same modified electrodes without an enzyme.

\subsection{Voltammetric response}

Figure $3 \mathrm{~b}$ demonstrates $\mathrm{CVs}$ of electrodes in the presence of $\mathrm{K}_{3} \mathrm{Fe}(\mathrm{CN})_{6}$ and $\mathrm{KCl}$. As it is clear that $\mathrm{Au}-\mathrm{CTAB} / \mathrm{GO}$

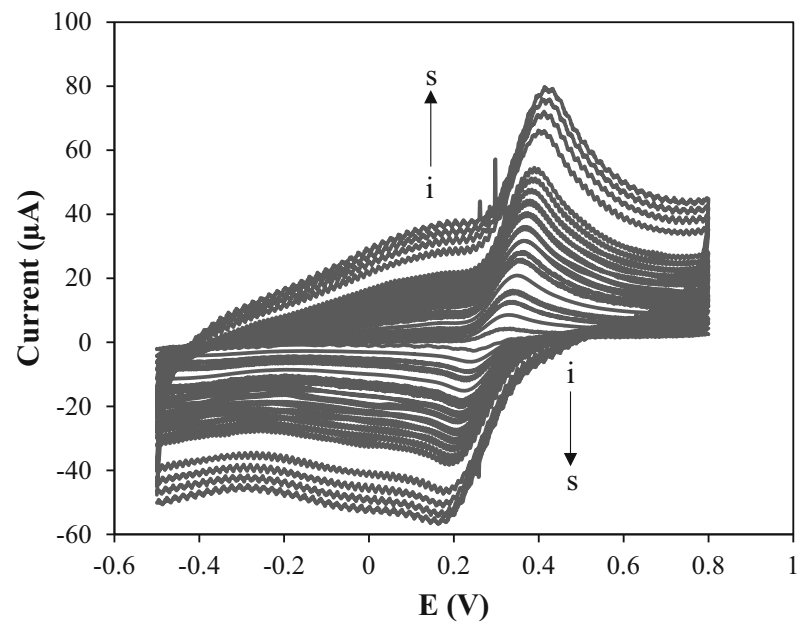

Figure 5. Cyclic voltammograms of the Lac biosensor in the solution comprising of $1.0 \times 10^{-1} \mathrm{M}$ phosphate buffer $(\mathrm{pH} 5.0)$ and $1.0 \times 10^{-3} \mathrm{M}$ catechol at diverse scan rates. Scan rates from (i) to (s) are $0.02,0.04,0.06,0.1,0.15,0.2,0.25,0.3,0.35,0.4,0.45,0.5$, $0.6,0.7,0.8,0.9$ and $1 \mathrm{~V} \mathrm{~s}^{-1}$, respectively.

has the largest redox currents and the immobilization of Lac reduces the amounts of redox currents. figure $3 \mathrm{c}$ shows the CVs of GCE and modified GCEs in the absence and presence of catechol. As can be seen, there is no any redox peak for the GCE in phosphate buffer. While a clear pair of redox peaks is seen for $\mathrm{Lac} / \mathrm{Au}-\mathrm{CTAB} / \mathrm{GO} / \mathrm{GCE}$ which can be related to the electroactive surface of the Lac biosensor. The $\mathrm{CVs}$ of GCE and Lac/Au-CTAB/GO/GCE in the presence of catechol are shown as well. According to figure $3 \mathrm{c}, \mathrm{Lac} / \mathrm{Au}-$ $\mathrm{CTAB} / \mathrm{GO} / \mathrm{GCE}$ has improved the oxidation and reduction peaks of catechol proportion to GCE due to smaller $\Delta E_{\mathrm{p}}$ and significant oxidation and reduction currents. 
The $\mathrm{pH}$ influences on the current peaks of catechol oxidation are revealed in figure $4 \mathrm{a}$. The changing of catechol redox reaction currents (oxidation and reduction) $v s$. $\mathrm{pH}$ is shown in figure $4 \mathrm{a}$ inset. Overall, the signal of current increased with the rising $\mathrm{pH}$ (up to $\mathrm{pH}$ 5), and then the current signal decreases at $\mathrm{pH}>5$. The peak currents of catechol gently diminished with the enhancing $\mathrm{pH}$ levels from 3.0 to 8.0 , ensuing from the lack of protons at upper $\mathrm{pH}$ values. It is obvious that the catechol is a protic aromatic molecule, which certainly undergoes deprotonation and turns to anion at higher $\mathrm{pHs}$. As a result, as the $\mathrm{pH}$ enhances to upper values, catechol

Table 1. The peak currents, potentials and the ratio of anodic and cathodic currents at different scan rates.

\begin{tabular}{lcllll}
\hline Scan rate, $\mathrm{V} \mathrm{s}^{-1}$ & $i_{\mathrm{p}}^{\mathrm{a}}, \mu \mathrm{A}$ & $i_{\mathrm{p}}^{\mathrm{c}}, \mu \mathrm{A}$ & $E_{\mathrm{p}}^{\mathrm{a}}, \mathrm{V}$ & $E_{\mathrm{p}}^{\mathrm{c}}, \mathrm{V}$ & $i_{\mathrm{p}}^{\mathrm{a}} / i_{\mathrm{p}}^{\mathrm{c}}$ \\
\hline 0.02 & 6.438 & -6.979 & 0.329 & 0.24 & 0.922 \\
0.04 & 9.011 & -9.73 & 0.336 & 0.233 & 0.926 \\
0.06 & 10.99 & -11.94 & 0.34 & 0.232 & 0.920 \\
0.1 & 14.04 & -15.09 & 0.347 & 0.227 & 0.930 \\
0.14 & 16.57 & -17.81 & 0.354 & 0.221 & 0.930 \\
0.16 & 17.99 & -19.33 & 0.361 & 0.212 & 0.931 \\
0.18 & 19.43 & -20.85 & 0.364 & 0.211 & 0.932 \\
0.2 & 20.11 & -21.41 & 0.366 & 0.21 & 0.939 \\
0.25 & 22.32 & -23.6 & 0.369 & 0.209 & 0.946 \\
0.3 & 24.52 & -25.91 & 0.371 & 0.204 & 0.946 \\
0.35 & 26.38 & -27.86 & 0.375 & 0.203 & 0.947 \\
0.4 & 28.05 & -29.44 & 0.379 & 0.201 & 0.953 \\
0.45 & 29.62 & -31.09 & 0.384 & 0.198 & 0.953 \\
0.5 & 30.79 & -32.21 & 0.387 & 0.194 & 0.956 \\
0.6 & 33 & -34.46 & 0.398 & 0.188 & 0.956 \\
0.7 & 35.21 & -36.76 & 0.406 & 0.186 & 0.956 \\
0.8 & 37.33 & -38.96 & 0.412 & 0.181 & 0.958 \\
0.9 & 38.67 & -40.2 & 0.41 & 0.178 & 0.962 \\
1 & 40.31 & -40.89 & 0.419 & 0.177 & 0.986 \\
\hline
\end{tabular}

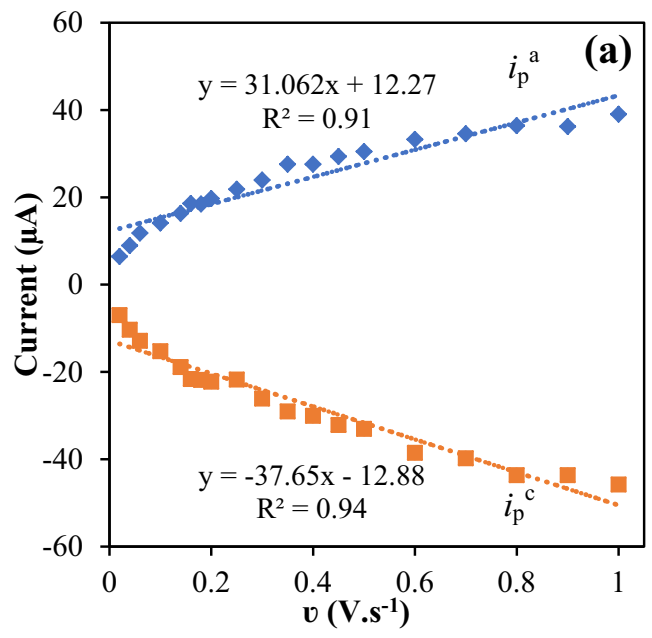

simply turns to anionic form, causing the electrostatic repulsion between the anionic form of catechol and the surface of reformed electrodes. Furthermore, the solution experienced a deficiency of protons, causing a trouble in electrochemical responses and decline in the current signal [35-39]. Therefore, $\mathrm{pH} 5$ was applied for more experiments of catechol detection at the modified electrode, and the electrochemical performances of Lac-modified electrode were examined using $\mathrm{CV}$ in phosphate buffer at $\mathrm{pH} 5$. According to figure $4 \mathrm{~b}$, the formal potential $\left(E^{\circ^{\prime}}\right)$ has changed $v s$. $\mathrm{pH}$ and the equation of $E^{\mathrm{o}^{\prime}}=-0.055 \mathrm{~V} / \mathrm{pH}+0.56\left(R^{2}=0.97\right)$ was obtained. The amount of slope (0.055) is near 0.059 (the slope value of the Nernstian equation), which means that the number of electrons and protons is equal.

Figure 5 demonstrates the CVs of $1.0 \times 10^{-3} \mathrm{M}$ catechol in phosphate buffer at diverse scan rates $(v)$. Moreover, the peak currents and potentials are shown in table 1 . The peaks of current signals are increased with enhancing $v$ (figure 6a) and the square root of $v$ (figure $6 \mathrm{~b}$ ). The correlation coefficient for the plot of currents $v s . v^{1 / 2}$ is higher than that of it for currents $v s$. $v$, demonstrating that a diffusion-controlled process overcomes the surface adsorption-controlled process $[40,41] . v$ influenced the cathodic and anodic peak potentials of the system, and as can be seen, the redox potentials were increased by increasing the logarithm of $v(\log v)$ (figure $7 a$ ).

Figure $7 \mathrm{a}$ demonstrates the relationship between the cathodic and anodic peak potentials $\left(E_{\mathrm{P}}^{\mathrm{c}}\right.$ and $\left.E_{\mathrm{P}}^{\mathrm{a}}\right)$ and a $\log v$ for the biosensor in the solution comprising of $1.0 \times 10^{-1} \mathrm{M}$ phosphate buffer (pH 5) and $1.0 \times 10^{-3} \mathrm{M}$ of catechol. For this biosensor, the peak potentials can be exhibited by Laviron [42] equations (1) and (2):

$$
E_{\mathrm{p}}^{\mathrm{a}}=E^{0^{\prime}}-\frac{2.3 R T}{(1-\alpha) n F} \log \frac{(1-\alpha) F n v}{R T k},
$$

Figure 6. (a) The influence of scan rate on cathodic and anodic currents of Lac biosensor. (b) The cathodic and anodic currents of Lac biosensor vs. square of the scan rate.

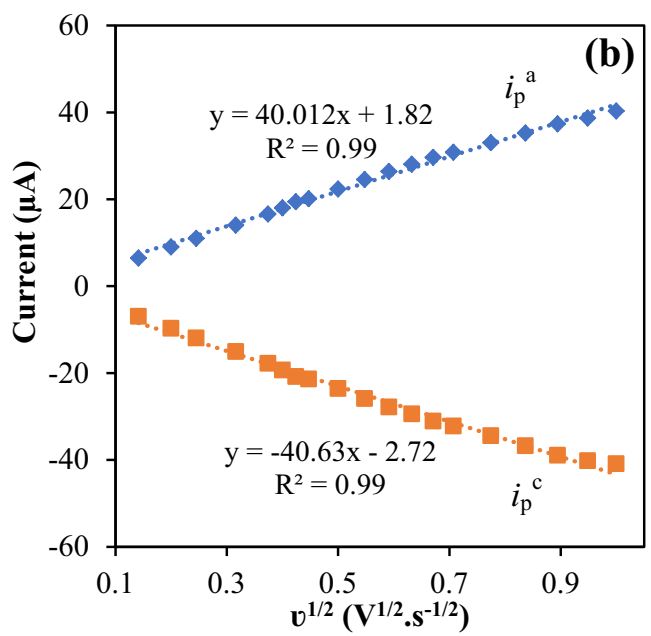



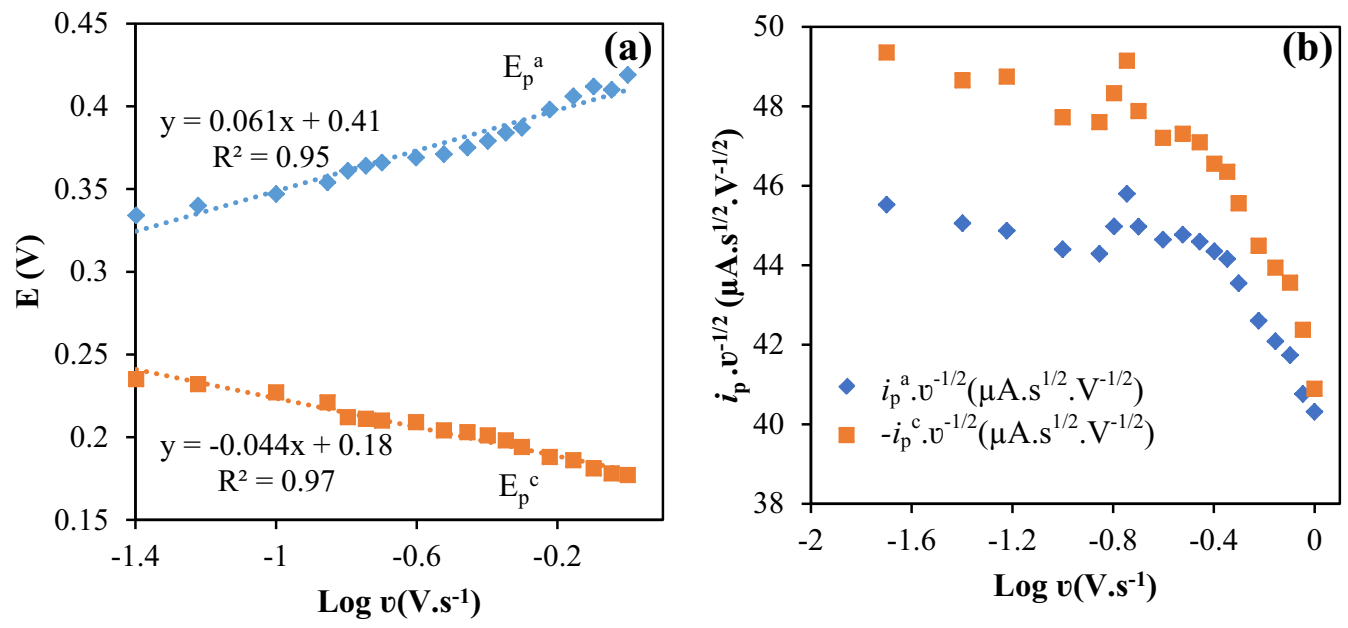

Figure 7. (a) Dependency of cathodic and anodic potentials scan rates in a logarithmic scale for the Lac biosensor. (b) The plot of $i_{\mathrm{p}}^{\mathrm{a}} \cdot v^{-1 / 2} v$ s. $\log v$.

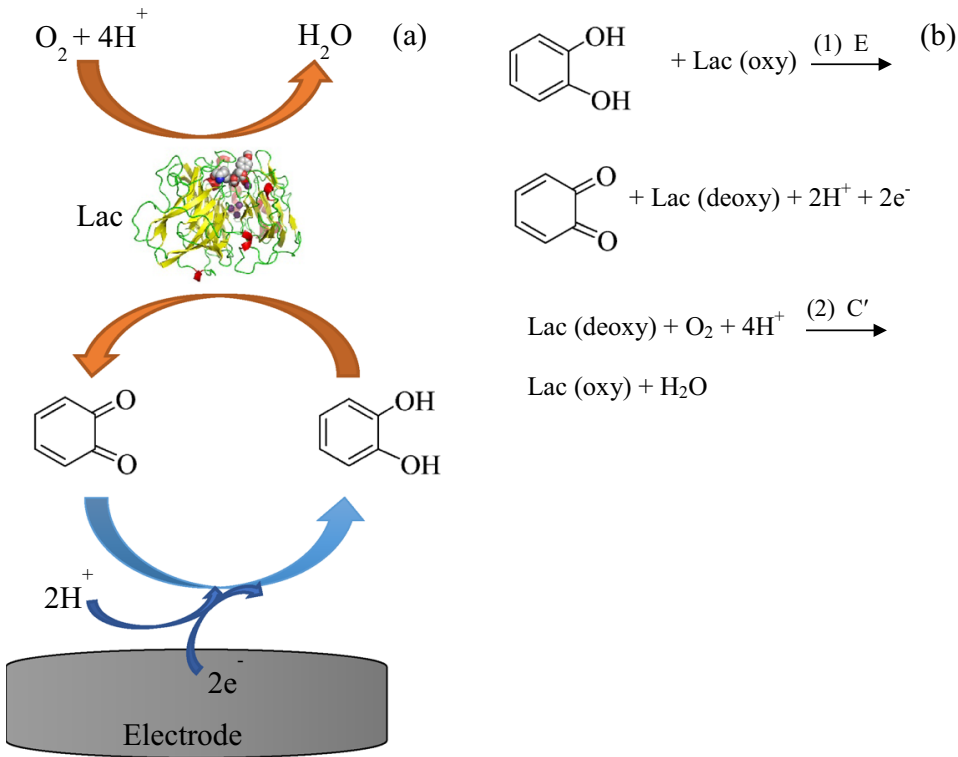

Scheme 1. (a) The schematic diagram and (b) the steps of reaction mechanism of $\mathrm{Lac} / \mathrm{Au}-\mathrm{CTAB} / \mathrm{GO} / \mathrm{GCE}$ in the presence of catechol.

Table 2. The interfering molecules for catechol determination $(100 \mu \mathrm{M})$.

\begin{tabular}{lr}
\hline Species & $C_{\text {species }} / C_{\text {catechol }}$ \\
\hline $\mathrm{Na}^{+}, \mathrm{K}^{+}, \mathrm{Br}^{-}, \mathrm{Cl}^{-}, \mathrm{NO}_{3}^{-}, \mathrm{H}_{2} \mathrm{PO}_{4}^{-}, \mathrm{HPO}_{4}^{2-}, \mathrm{Ca}^{2+}$ & 1000 \\
Alanine, glycine, phenylalanine, glucose, citric acid & 1000 \\
Phenol, ascorbic acid & 10 \\
Uric acid & 5 \\
Pyrogallol, dopamine & 1 \\
\hline
\end{tabular}

$$
\begin{aligned}
\log k_{\mathrm{s}}= & \alpha \log (1-\alpha)+(1-\alpha) \log \alpha \\
& -\log \frac{R T}{n F v}-\frac{\alpha(1-\alpha) F n \Delta E_{\mathrm{p}}}{2.3 R T},
\end{aligned}
$$

where $n, T, F$ and $R$ are the number of electrons, temperature, Faraday constant and gas constant, respectively; $\alpha$ and $k_{\mathrm{s}}$ are the electron transfer coefficient and heterogeneous electron 
transfer rate constant, respectively. Assuming $0.3<\alpha<0.7$ is common, it could be resolved that when $\alpha$ is equal to $0.33, n$ will be obtained as 2.0 using the slope of redox

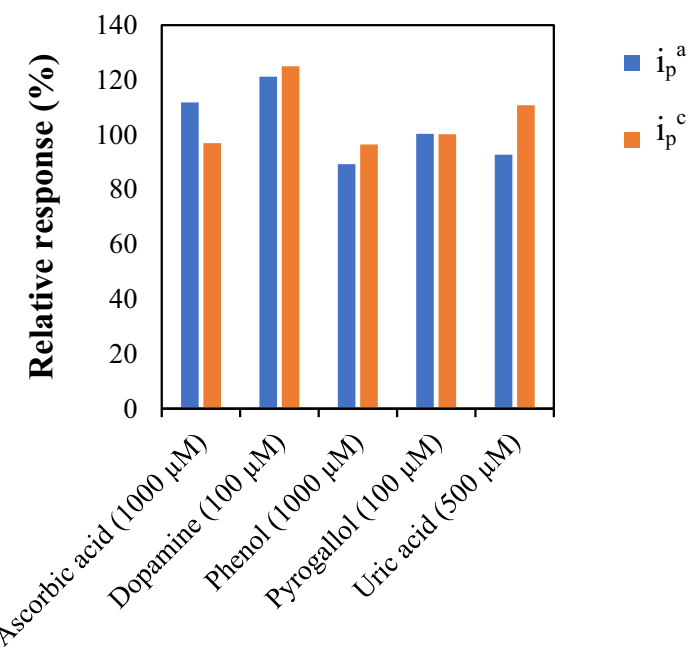

Figure 8. The biosensor responses to catechol $\left(10^{-4} \mathrm{M}\right)$ in the presence of interfering molecules.

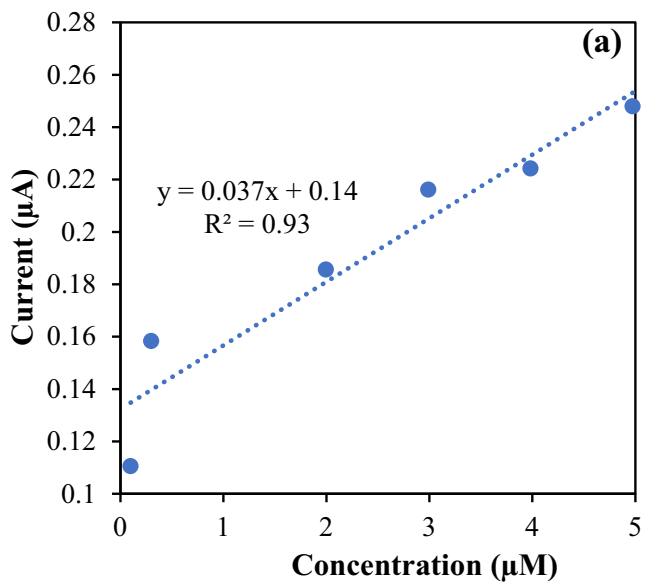

potential changes $v s$. logarithm of scan rate that indicates the electron transfer process is inclusive in the rate-limiting step [43]. Consequently, the redox reaction of catechol is a 2-electron transfer route and also, the number of protons is equal to 2 . Also, the $k_{\mathrm{s}}$ could be estimated to be $0.41 \mathrm{~s}^{-1}$ which is in agreement with previously reported values of $k_{\mathrm{s}}$ for different Lac biosensors [44].

To postulate the reaction mechanism, it is needed to examine the following: (1) verifying the ratio of $i_{\mathrm{p}}^{\mathrm{a}} / i_{\mathrm{p}}^{\mathrm{c}}$ is $<1$ and it increased with enhancing the scan rate. (2) The plot of $i_{\mathrm{p}}^{\mathrm{a}} \cdot v^{-1 / 2} v s . \log v$ can be seen in the reducing form as shown in figure $5 \mathrm{~b}$. These evidences confirm that the mechanism is $\mathrm{EC}$ or $\mathrm{EC}^{\prime}$ [45]. When the oxidized form of Lac affects on catechol, it causes formation of quinone, two electrons and two protons; this is the first step. Then, reduced Lac can be changed to the oxidized form again by reduction of oxygen to water; this is the second step and it is a chemical reaction that produces oxidized Lac that can react again for catechol oxidation; therefore, the mechanism is $\mathrm{EC}^{\prime}$. Scheme 1 shows the reactions on the biosensor surface. Additionally, the electrochemical mechanism of the proposed biosensor is not reversible and it can be determined using the behaviour of the scan rate effect; the electrochemical

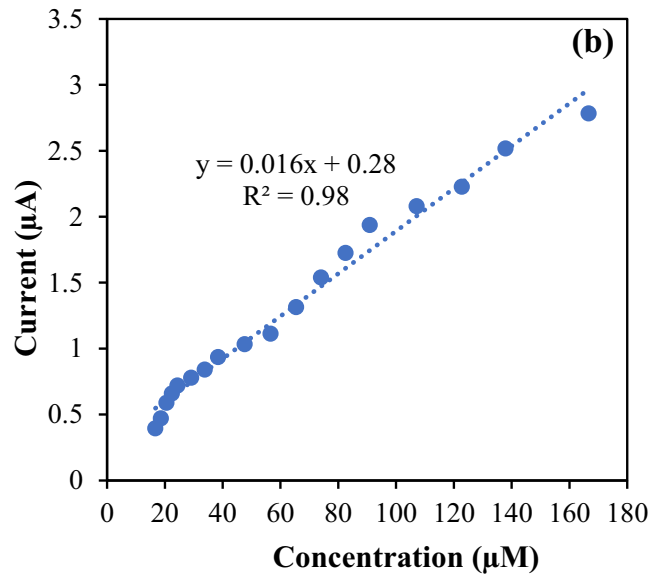

Figure 9. Catechol calibration curves for the Lac biosensor in two linear ranges: (a) 0.1-5 and (b) $16.7-166 \mu \mathrm{M}$.

Table 3. Comparable methods for determination of catechol.

\begin{tabular}{|c|c|c|c|c|c|}
\hline Electrode & Optimum pH & Linear range, $\mu \mathrm{M}$ & $\mathrm{LOD}, \mu \mathrm{M}$ & Sensitivity, $\mu \mathrm{A} \mathrm{mM}^{-1}$ & Reference \\
\hline $\mathrm{Lac} / \mathrm{N}-\mathrm{OMC} / \mathrm{PVA} / \mathrm{AuE}$ & 5 & $0.39-8.98$ & 0.31 & 290 & {$[46]$} \\
\hline $\mathrm{Lac} / \mathrm{AP}-\mathrm{rGO} / \mathrm{chit} / \mathrm{GCE}$ & 4.5 & $15-700$ & 7 & 14.16 & [4] \\
\hline Lac/AgNPs/CMC/cellulose/GCE & 5 & $4.98-3650$ & 1.64 & 37.8 & [47] \\
\hline PDA-Lac-NiCNFs/MGCE & 5.5 & $1-9100$ & 0.69 & 18.4 & [48] \\
\hline Lac-FSM7.0-GCE & 5 & $2-100$ & 2 & - & [49] \\
\hline PEDOT-GONs-Lac/GCE & 6 & $0.036-0.35$ and $0.35-2.5$ & 0.032 & $2.981 \times 10^{4}, 3.417 \times 10^{3}$ & {$[50]$} \\
\hline $\mathrm{Lac} / \mathrm{Au}-\mathrm{CTAB} / \mathrm{GO} / \mathrm{GCE}$ & 5 & $0.1-5$ and $16.7-166$ & 1.5 & 37,16 & This work \\
\hline
\end{tabular}

AuE, gold electrode; N-OMC, nitrogen-containing ordered mesoporous carbon; PVA, polyvinyl alcohol; rGOs, reduced graphene oxides; 1-AP, 1-aminopyrene; chit, chitosan; CMC, carboxymethyl cellulose; MGCE, magnetic glassy carbon electrode; PDA, polydopamine; NiCNFs, nickel NP-loaded carbon nanofibres; FSM7.0, $7.0 \mathrm{~nm}$ pore diameter; PEDOT, poly(3,4-ethylenedioxythiophene); GONs, graphene oxide nanosheets. 
reaction on the biosensor surface is quasi-reversible, due to the following reasons: (1) enhancing of redox peak currents by increasing $v^{1 / 2}$, (2) both the numbers of electrons and protons are equal to 2 , and $\Delta E_{\mathrm{p}}$ is $>0.059 \mathrm{~V}$ even at low scan rates (the $\Delta E_{\mathrm{p}}$ value was $0.124 \mathrm{~V}$ at the scan rate of $\left.1.0 \times 10^{-1} \mathrm{~V} \mathrm{~s}^{-1}\right)$, (3) $\Delta E_{\mathrm{p}}$ is increased by increasing $v$, and (4) changing of cathodic potentials to negative values by increasing $v[45]$.

Also, the four electrodes were fabricated to investigate the reproducibility of the Lac biosensor by the $\mathrm{CV}$ technique and relative standard deviation was obtained as $5.59 \%$ for catechol $\left(1.0 \times 10^{-3} \mathrm{M}\right)$ determination. The biosensor stability was examined by the $\mathrm{CV}$ response to $1.0 \times 10^{-3} \mathrm{M}$ of catechol. After 1 month, the Lac biosensor lost about $37.34 \%$ of its first response.

\subsection{Interference study}

The potential impacts of some overlapping products, including anionic and cationic species, citric acid, some amino acids, glucose, uric acid, ascorbic acid, dopamine, phenol and pyrogallol were used to sense catechol under the same conditions. According to table 2, it perceives that the side effects of organic and inorganic materials are insignificant except for pyrogallol and dopamine. These two interferences, especially dopamine, have the most structural similarity to catechol. For better evaluation of the response of serious interferences including phenol, pyrogallol, ascorbic acid, uric acid and dopamine is shown in figure 8 . The biosensor can distinguish catechol in the solution containing potential interferents. There are two distinguishable oxidation peaks for catechol and some interferences including pyrogallol, ascorbic acid and uric acid and their oxidation peaks appear at $0.257,0.202$ and $0.468 \mathrm{~V}$, respectively; while the oxidation peak of catechol appears at $0.35 \mathrm{~V}$.

\subsection{Calibration curve and detection limit}

The minimum concentration that can be detected is named as limit of detection (LOD), this is the point where we are able to just discriminate signals from the backgrounds. Due to the high sensitivity of the DPV technique, it was used for catechol detection and LOD calculation. A sharp cathodic peak was exhibited using the subsequent circumstances: modified GCE as a working electrode, DPV amplitude in phosphate buffer $(\mathrm{pH} 5)$ containing catechol $\left(1.0 \times 10^{-3} \mathrm{M}\right)$. Catechol indicated two linear ranges from $0.1 \times 10^{-6}$ to $5 \times 10^{-6} \mathrm{M}$ and $16.7 \times 10^{-6}$ to $166 \times 10^{-6} \mathrm{M}$ (figure $9 \mathrm{a}$ and $\mathrm{b}$ ) and the LOD was calculated as $1.5 \times 10^{-6} \mathrm{M}$. This Lac biosensor was compared with some enzymatic-based biosensors, and the resulting data are shown in table 3 . From table 3 , it is clear that the presented biosensor has a wide linear range and its LOD is lower when compared with some other biosensors.

\section{Conclusions}

A new and simple GCE fabrication was described with the nanosheets of $\mathrm{GO}$ and $\mathrm{Au}-\mathrm{CTAB}$ for the immobilization of Lac and direct electrochemical detection of catechol. Electrodeposition of Au-CTAB onto GO/GCE makes an electroactive surface that showed high current and very low $R_{\text {et }}$ compared with GO/GCE and Au-CTAB/GCE. Also, it causes to immobilize biological species especially Lac in this work; usage and immobilization of Lac make a selective and sensitive catechol biosensor. According to the results, Lac was successfully immobilized onto the modified electrode via electrostatic adsorption. Different techniques were used to characterize the biosensor. SEM and FESEM showed the coating morphologies on the GCE. SEM images demonstrate two-dimensional morphology of the GO, the electrodeposited $\mathrm{Au}-\mathrm{CTAB}$, and FESEM showed the immobilized Lac. The Lac biosensor displayed the large $R_{\text {et }}$ when compared with the other modified GCEs. Biosensor cyclic voltammograms showed a direct electron transfer reaction between the electrode and Lac with two electrons and two protons and a quasi-reversible mechanism. It should be noticed that the $\mathrm{EC}^{\prime}$ mechanism was determined for the electrochemical reaction. Moreover, $\alpha$ and $k_{\mathrm{s}}$ were obtained as 0.33 and $0.41 \mathrm{~s}^{-1}$, respectively. For this biosensor, two linear ranges and low LOD were obtained. Furthermore, the biosensor had acceptable reproducibility and storage stability and satisfying selectivity.

\section{References}

[1] Chen H, Yao J, Wang F, Zhou Y, Chen K, Zhuang R et al 2010 Sci. Total Environ. 4081043

[2] Han E, Yang Y, He Z, Cai J, Zhang X and Dong X 2015 Anal. Biochem. 486102

[3] Wang C, Feng Y, Gao P, Ren N and Li B L 2012 Sci. Total Environ. 431366

[4] Zhou X H, Liu L H, Bai X and Shi H C 2013 Sens. Actuators B Chem. 181661

[5] Gorla F A, Duarte E H, Sartori E R and Tarley C R T 2016 Microchem. J. 12465

[6] Ren J, Kang T F, Xue R, Ge C N and Cheng S Y 2011 Microchim. Acta 174303

[7] Feng S, Zhang Y, Zhong Y, Li Y and Li S 2014 J. Electroanal. Chem. 7331

[8] Maya F, Estela J M and Cerdà V 2010 Talanta 811

[9] Yang J, Li D, Fu J, Huang F and Wei Q 2016 J. Electroanal. Chem. 76616

[10] Nazari M, Kashanian S and Rafipour R 2015 Spectrochim. Acta, Part A 145130

[11] Li D W, Luo L, Lv P F, Wang Q Q, Lu K Y, Wei A F et al 2016 Bioinorg. Chem. Appl. 2016536036110

[12] Karim F and Fakhruddin A 2012 Rev. Environ. Sci. Biotechnol. 11261

[13] Mohammad R, Ahmad M and Heng L Y 2013 Sensors 13 10014 
[14] Wu C, Liu Z, Sun H, Wang X and Xu P 2016 Biosens. Bioelectron. 79843

[15] Rodríguez-Delgado M M, Alemán-Nava G S, RodríguezDelgado J M, Dieck-Assad G, Martínez-Chapa S O, Barceló D et al 2015 TrAC, Trends Anal. Chem. 7421

[16] Cabaj J, Jędrychowska A, Zając D, Krawiec S and Sołoducho J 2016 Int. J. Electrochem. Sci. 11609

[17] Chen B, Xu W Q, Pan X R and Lu L 2015 Int. J. Biol. Macromol. 7639

[18] Vasilescu I, Eremia S A V, Kusko M, Radoi A, Vasile E and Radu G L 2016 Biosens. Bioelectron. 75232

[19] Morozova O, Shumakovich G, Shleev S and Yaropolov Y I 2007 Appl. Biochem. Microbiol. 43523

[20] Dai Z, Guo M, Wang X, Wang H and Chen W 2014 J. Nanomater. 20142

[21] Portaccio M, Di Tuoro D, Arduini F, Moscone D, Cammarota M, Mita D G et al 2013 Electrochim. Acta 109340

[22] Franzoi A C, Vieira I C, Dupont J, Scheeren C W and de Oliveira L F 2009 Analyst 1342320

[23] Gutierrez-Sanchez C, Shleev S, De Lacey A L and Pita M 2015 Chem. Pap. 69237

[24] Boujakhrout A, Jimenez-Falcao S, Martinez-Ruiz P, Sanchez A, Diez P, Pingarron J M et al 2016 Analyst 1414162

[25] Yang L, Zhao H, Li Y and Li C P 2015 Sens. Actuators B 2071

[26] Liu J, Lin G, Xiao C, Xue Y, Yang A, Ren H et al 2015 Biosens. Bioelectron. 7182

[27] Veerapandian M, Lévaray N, Lee M H, Giasson S, Zhu X et al 2015 ACS Appl. Mater. Interfaces 714552

[28] Ma H, Yin B, Wang S, Jiao Y, Pan W, Huang S et al 2004 ChemPhysChem $\mathbf{5} 68$

[29] Bakshi M S, Sharma P and Banipal T S 2007 Mater. Lett. 61 5004

[30] Valezi C F, Duarte E H, Mansano G R, Dall'Antonia L H, Tarley C R T and Sartori E R 2014 Sens. Actuators B 205234

[31] Khan Z, Al-Thabaiti S A and Bashir O 2016 Dyes Pigm. 124 210
[32] Rodríguez-Fernández J, Pérez-Juste J, Mulvaney P and LizMarzán L M 2005 J. Phys. Chem. B 10914257

[33] Marcano D C, Kosynkin D V, Berlin J M, Sinitskii A, Sun Z, Slesarev A et al 2010 ACS Nano 44806

[34] Pavia D L, Lampman G M, Kriz G S and Vyvyan J A 2014 Introduction to spectroscopy, 5 edn (USA: Cengage Learning)

[35] Song D, Xia J, Zhang F, Bi S, Xiang W, Wang Z et al 2015 Sens. Actuators B 206111

[36] Chen R, Wang Q, Li Y, Gu Y, Tang L and Li C 2015 RSC Adv. 5 44165

[37] Quan D and Shin W 2004 Electroanalysis 161576

[38] Fan L, Li X and Kan X 2016 Electrochim. Acta 213504

[39] Qi H and Zhang C 2005 Electroanalysis 17832

[40] Qu J, Lou T, Wang Y, Dong Y and Xing H 2015 Anal. Lett. 48 1842

[41] Sarika C, Shivakumar M, Shivakumara C, Krishnamurthy G, Narasimha Murthy B and Lekshmi I 2017 Artif. Cells Nanomed. Biotechnol. 45625

[42] Laviron E 1979 J. Electroanal. Chem. Interfacial Electrochem. 10119

[43] Rafipour R, Kashanian S and Tarighat F A 2014 IET Nanobiotechnol. 8196

[44] Li G, Sun K, Li D, Lv P, Wang Q, Huang F et al 2016 Colloids Surf. A $\mathbf{5 0 9} 408$

[45] Bard A J, Faulkner L R, Leddy J, Zoski C G 2001 Electrochemical methods: fundamentals and applications, 2 edn. (New York: Wiley)

[46] Guo M, Wang H, Huang D, Han Z, Li Q, Wang X et al 2014 J. Sci. Technol. Adv. Mater. 15035005

[47] Fu J, Li D, Li G, Huang F and Wei Q 2015 J. Electroanal. Chem. 73892

[48] Li D, Luo L, Pang Z, Ding L, Wang Q, Ke H et al 2014 ACS Appl. Mater. Interfaces 65144

[49] Shimomura T, Itoh T, Sumiya T, Hanaoka T, Mizukami F and Ono M 2011 Sens. Actuators B 153361

[50] Maleki N, Kashanian S, Maleki E and Nazari M 2017 Biochem. Eng. J. 1281 